\title{
Biofilm forming ability of intermediate and saprophytic Leptospira on abiotic and biotic surfaces
}

\author{
Kasing Apun`, Jennifer Jalan, Chai Fung Pui, Lesley Maurice Bilung, Hashimatul Fatma Hashim, Anisa Aina \\ Nadiah binti Md Ahsan and Rennielyn Rupert
}

Faculty of Resource Science and Technology, Universiti Malaysia Sarawak, 94300 Kota Samarahan, Sarawak. Email: kasing@unimas.my

\begin{abstract}
Aims: Leptospira spp. has the ability to develop biofilm communities and this attribute is an essential factor to leptospiral pathogenesis. This study aims to assess and quantify the biofilm forming ability of intermediate and saprophytic Leptospira strains.

Methodology and results: The biofilm assay was quantified on microtitre polystyrene plates (abiotic) and wood chips (Jelutong Paya hardwood) over a duration of 11 days. Phase contrast light microscope was used to assess the structure of the on the surface. The biofilm production on wood chips surface were approximately one times higher than on polystyrene plate surface indicating Leptospira strains were capable of forming higher quantity of biofilm on biotic surface compared to abiotic surface by both intermediate and saprophytic Leptospira. A significant difference $(p<0.05)$ exists in biofilms produced by Leptospira on wood surface which formed more biofilm than on polystyrene surface. The strongest biofilm producer is intermediate strain G14 with OD 600 of $2.283 \pm 0.180$ and $\mathrm{OD}_{600}$ of $2.333 \pm 0.037$, on polystyrene and wood surface, respectively. Visualisation of biofilm by phase-contrast microscopy of two representative strains correlated with the OD values and the colour intensity of stained microtitre plates and wood surfaces. The biofilm formed comprises of a three-step process are adherence ( $1^{\text {th }}$ to $24^{\text {th }} \mathrm{h}$ ), maturation ( $6 \mathrm{t}^{\mathrm{h}}$ to $7^{\text {th }}$ day) and detachment $\left(9^{\text {th }}\right.$ to $11^{\text {th }}$ day) of biofilms.

Conclusion, significance and impact of study: The contact time of intermediate pathogenic strains was faster compared to saprophytic strain, indicating the biofilm forming ability is related to the level of pathogenicity of Leptospira strains.
\end{abstract}

Keywords: Polystyrene, woods, biofilm formation, Leptospira, intermediate, saprophytic, pathogenicity

\section{INTRODUCTION}

Leptospirosis is a zoonotic disease spread by infected animals such as mice, fish and birds. It is a re-emerging disease that is caused by pathogenic Leptospira. It is transmitted through contact with urine, water, or soil contaminated by urine from animal reservoirs, such as rodents, dogs, and livestock (Guerra, 2009). Direct penetration of Leptospira sp. through the conjunctiva or surface epithelium could also cause the transmission to occur (Russ et al., 2003). Leptospira spp. can be divided into three types which are known as saprophytic, intermediate, and pathogenic (Ristow et al., 2008). In Malaysia, the Prevention and Control of Infectious Diseases Act 1988 has officially published leptospirosis as a notifiable disease in 2010.

More than 500,000 cases of severe leptospirosis occur each year, with a mortality rate $5-20 \%$ (WHO, 1999). A total of 13,176 leptospirosis cases were reported from the year 2014 until July 2015 in Malaysia, whereby 122 were death cases (Ministry of Health Malaysia,
2015). In Sarawak, a total of 163 Leptospirosis cases were reported caused by leptospirosis according to the Sarawak Weekly Epid News (March 2015). In the recent study conducted by Pui et al. (2015), pathogenic and intermediate Leptospira strains at two national parks in Sarawak were detected by PCR analysis. However, there are limited epidemiological studies of leptospirosis caused by intermediate strains of Leptospira.

Like other spirochaetes, Leptospira spp. has the ability to alter their morphology depending on the environmental conditions. The changes include the aggregation and colonization of single planktonic cells into the biofilm mode. In previous studies, bacteria have been proven to be able to exhibit biofilm in both abiotic and biotic surfaces. The potential of Leptospira in forming biofilms on these surfaces play an important role, not only for survival strategy but also to ensure it is successful in disease transmission and pathogenesis of these species (Iraola et al., 2016). The capability of the bacteria to form biofilm on abiotic and biotic surfaces causes the increase in the persistency of these species. 
To our best knowledge, several studies on biofilm are mainly on saprophytic and pathogenic Leptospira. The knowledge about intermediate strains and studies related to its pathogenicity is limited. Hence, this study was conducted to determine the relationship of contact time, biofilm forming ability with the level of pathogenicity of these species on abiotic and biotic surfaces.

\section{MATERIALS AND METHODS}

\section{Bacterial strains and growth condition}

All intermediate and saprophytic Leptospira strains were obtained from Microbiology Laboratory from Department of Molecular Biology, Faculty Resource Science and Technology, Universiti Malaysia Sarawak. The isolates were incubated in EMJH which contain EMJH base, $0.1 \mathrm{~g}$ of 5-flurouracil and enrichment media at room temperature. Final concentration of the culture was $10^{6}$ to $10^{8} \mathrm{CFU} / \mathrm{mL}$ as suggested by Ristow et al. (2008). All cultures were incubated at $30{ }^{\circ} \mathrm{C}$ for 30 days. Tables 1 and 2 show the selected isolates from the culture collection.

\section{Dark field microscopic analysis}

Selected cultures were observed at $400 \times$ magnification under dark field microscope (Olympus Corporation,
Japan) after 30 days. Each strain was placed on sterile glass slides for observation. Leptospira were observed as a hook-like end, thin and motile. The images of the motile Leptospira were captured and recorded for further analysis. Samples that were positive for Leptospira were subcultured into EMJH medium, Difco ${ }^{\mathrm{TM}}$ Medium Base EMJH (Becton, Dickinsom and company, USA) for further analysis (Benacer et al., 2013).

\section{Preparation of Leptospira isolates culture for biofilm on abiotic surface (microtitre polystyrene surface)}

Before performing biofilm assay, the optical density of each isolates was measured at $420 \mathrm{~nm}$ with OD values of 0.3 to 0.4 corresponding to $10^{6}$ to $10^{8} \mathrm{CFU} / \mathrm{mL}$ of cells. Serial dilutions were carried out to ensure the final concentration of cells in each well was standardized to $10^{6} \mathrm{CFU} / \mathrm{mL}$ which indicating the culture is in midexponential phase. The biofilms were formed and measured in 24-well polystyrene plates, Tissue Culture Test Plate 24 (TPP®, Switzerland). Afterwards, the bacterial cultures were filled into the wells and the polystyrene plates were sealed during incubation to avoid from desiccation. Incubation were carried out at different intervals $(24,48,72,96,120,144,168,192,216,240$, $264 \mathrm{~h})$.

Table 1: Intermediate Leptospira strains used in biofilm assay from various sources.

\begin{tabular}{|c|c|c|c|}
\hline No. designation & Isolates strain & Sources & Locality \\
\hline G12 & $\begin{array}{l}\text { Leptospira wolffii serovar Khorat strain } \\
\text { Khorat-H2 }\end{array}$ & Soil & National Service Training Centre, Miri \\
\hline G14 & $\begin{array}{l}\text { Leptospira wolffii serovar Khorat strain } \\
\text { Khorat-H2 }\end{array}$ & Soil & Kubah National Park, Kuching \\
\hline G9 & Leptospira sp. MS341 & Water & National Service Training Centre, Miri \\
\hline G11 & $\begin{array}{l}\text { Leptospira wolffii serovar Khorat strain } \\
\text { Khorat-H2 }\end{array}$ & Water & National Service Training Centre, Miri \\
\hline G29 & $\begin{array}{l}\text { Leptospira wolffii serovar Khorat strain } \\
\text { Khorat-H2 }\end{array}$ & Rat liver & Kampung Sungai Mata, Kota Samarahan \\
\hline G1 & $\begin{array}{l}\text { Leptospira wolffii serovar Khorat strain } \\
\text { Khorat-H2 }\end{array}$ & Soil & Tanjung Datu National Park, Kuching \\
\hline
\end{tabular}

Table 2: Saprophytic Leptospira strains used in biofilm assay from various sources.

\begin{tabular}{|c|c|c|c|}
\hline No. designation & Isolate strain & Sources & Locality \\
\hline S4 & Leptospira meyeri strain Semaranga_DB49 & Soil & UNIMAS, Kota Samarahan \\
\hline S11 & Leptospira meyeri strain Semaranga_DB49 & Soil & National Service Training Centre, Miri \\
\hline $\mathrm{S} 21$ & Leptospira meyeri strain 19CAP & Soil & Medan Niaga Satok, Kuching \\
\hline S3 & Leptospira meyeri strain Patoc strain "Patoc & Water & $\begin{array}{l}\text { Juara National Service Training Centre, } \\
\text { Kuching }\end{array}$ \\
\hline S5 & Leptospira meyeri strain Semaranga_DB49 & Water & National Service Training Centre, Miri \\
\hline S12 & Leptospira meyeri strain Semaranga_DB49 & Water & Kubah National Park, Kuching \\
\hline Patoc & $\begin{array}{l}\text { Leptospira biflexa serovar Patoc strain 'Patoc } \\
1 \text { (positive control) }\end{array}$ & - & $\begin{array}{l}\text { Institute of Medical Research, Malaysia } \\
\text { (IMR) }\end{array}$ \\
\hline
\end{tabular}


Malays. J. Microbiol. Vol 14(4) Special Issue 2018, pp. 313-319 DOI: http://dx.doi.org/10.21161/mjm.144183

\section{Biofilm assay on abiotic surface}

Microtitre plate assay was conducted in triplicate on 24well microtitre polystyrene plates. This method was carried out according to Pui et al. (2017). Briefly, the cultures were aspired, rinsed and fixed on the polystyrene surface. Crystal violet was used to stain the adherent cells on the surface and the remaining further dissolved with ethanol/acetone solution. By using a spectrophotometer (Metertech Inc. SF-880, Taiwan), the optical density of each isolates was measured at $600 \mathrm{~nm}$.

\section{Preparation of Leptospira isolates culture for biofilm on biotic surface (woods chips)}

Mid-exponential cultures $\left(10^{6}-10^{8} \quad \mathrm{CFU} / \mathrm{mL}\right)$ were prepared by incubating the cultures in EMJH broth for a week. To ensure the final concentration of cultures is $10^{6}$ $\mathrm{CFU} / \mathrm{mL}$, serial dilutions were performed. Study on biotic surface was achieved by using wood surface for attachment and biofilm assay on biotic surfaces. Before biofilm assay, the wood samples known as Jelutong Paya Hardwood (Dyera costulata) were cut using a fine-toothed saw to provide a precise and accurate size of wood chips $(1 \mathrm{~cm} \times 0.5 \mathrm{~cm} \times 0.5 \mathrm{~cm})$. The hardwood was obtained from the laboratory of department of Plant Science and Environmental Ecology. Subsequently, the chips were rinsed using a detergent and air-dried. Afterwards, the chips were placed into a hot air oven at $75^{\circ} \mathrm{C}$ for $30 \mathrm{~min}$. The chips were then filled into the well plates along with 1 $\mathrm{mL}$ of bacterial cultures. To prevent from desiccation of the cultures, the plates were sealed with parafilm (Adetunji et al., 2011).

\section{Biofilm assay on biotic surface}

Biofilm was assayed in triplicate on the wood chips representing biotic surface. This technique of biofilm assay specifically on wood surface was based on the method of Adetunji et al. (2011). At the end of each incubation period at $24 \mathrm{~h}$ intervals $(24,48,72,96,120$, 144, 168, 192, 216, 240, 264 h), a set of chips were aseptically removed from the bacterial cultures to the new well plates for biofilm quantification using crystal violet binding assay. Each set of wood chips were rinsed once using $1 \mathrm{~mL}$ of PBS to remove non-adherent cells on the wood surfaces. Then, $2.5 \mathrm{~mL}$ of methanol per chips were used to fix the remaining adhered bacterial cells. Each chip was stained using $0.9 \mathrm{~mL}$ of $0.1 \%$ crystal violet for 15 minutes and then the excess stain was rinsed three times with $1 \mathrm{~mL}$ of PBS. Afterwards, the chips were air-dried for another $15 \mathrm{~min}$ before re-solubilized the dye bound to the adherent cells using $2.5 \mathrm{~mL}$ of $33 \%(\mathrm{v} / \mathrm{v})$ glacial acetic acid. Lastly, the re-solubilized liquid was poured into cuvettes for measurement of optical density (OD) using a spectrophotometer (Metertech Inc. SF-880, Taiwan) at wavelength of $420 \mathrm{~nm}$. Glacial acetic acid was used as a blank.

\section{Biofilm formation categories}

The optical density of every strain was calculated using optical density cut-off value (ODc) which defined as three standard deviation above the mean optical density of the negative control which adapted from Stepanovic et al. (2000). The four classes known as OD $\leq$ ODc (non-biofilm producer), $\mathrm{ODc}<\mathrm{OD} \leq 2 \times \mathrm{ODc}$ (weak biofilm producer), $2 \times$ ODc $<$ OD $\leq 4 \times$ ODc (moderate biofilm producer) and $4 \times$ ODc $<$ OD (strong biofilm producer). The biofilm producers calculated in percentage represent the amount of biofilm formation.

\section{Data analysis}

Statistical analysis was performed by using Microsoft Excel (version 14.0, release 1.5, California, US). A significance level of $5 \%(p<0.05)$ was set for statistically analyses. Differences between triplicate means for the isolates were evaluated using repeated measures oneway ANOVA, followed by Post-Hoc Bonferoni test to differentiate the biofilm forming ability of Leptospira.

\section{RESULTS}

\section{Growth of Leptospira}

The $\mathrm{OD}_{420}$ for Leptospira species obtained were in the range of 0.3 to 0.4 as shown in Table 3 . The OD readings obtained for intermediate isolates at $420 \mathrm{~nm}$ were tabulated in Table 3 . The acceptable range of OD values for Leptospira is between 0.3 to 0.4 which indicates the acceptable number of colonies $\left(10^{6}-10^{8} \mathrm{CFU} / \mathrm{mL}\right)$ to start a biofilm assay (Sutton, 2006). This indicates the microbial population in these samples were in the acceptable range to initiate biofilm experiment.

Table 3: The OD values obtained for Leptospira at 420 $\mathrm{nm}\left(10^{6}-10^{8} \mathrm{CFU} / \mathrm{mL}\right)$.

\begin{tabular}{llll}
\hline Intermediate & OD $_{420}$ & Saprophytic & OD $_{420}$ \\
\hline G9 & 0.335 & S3 & 0.367 \\
G11 & 0.347 & S4 & 0.344 \\
G12 & 0.382 & S5 & 0.398 \\
G14 & 0.400 & S11 & 0.379 \\
G29 & 0.401 & S12 & 0.341 \\
G1 & 0.371 & S21 & 0.372 \\
- & - & PATOC & 0.361 \\
\hline
\end{tabular}

Development of biofilm on abiotic surface (microtitre polystyrene surface)

On microtitres polystyrene surface, this study showed that intermediate strains G1 (positive control), G12 and G14 (Figure 1) formed stronger biofilms compared to G9 and G11. The wells of G14 were stained more with crystal violet than the wells of $\mathrm{G} 9$ and $\mathrm{G} 11$ which was observed on day $4^{\text {th }}$. This finding shows that the biofilm produced by $\mathrm{G} 14$ is strong to withstand the rinsing process during the assay of G9 recorded as the weakest strain biofilm 
Malays. J. Microbiol. Vol 14(4) Special Issue 2018, pp. 313-319 DOI: http://dx.doi.org/10.21161/mjm.144183

forming on the well plates based on the intensity of crystal violet staining. As for saprophytic strain, S12 showed the highest colour intensity on day 6 with mean optical density values of 2.066 (Figure 2). From the result, $57.14 \%$ of isolates developed mature biofilms on day 6 and $42.86 \%$ on day 8 of incubation. On the contrary, S3 and $\mathrm{S} 11$ had the lowest colour intensity in which the biofilms were only exhibited on day eight with optical density values of 1.450 and 1.565 respectively while rapidly dispersed afterwards. This can be seen in the delayed biofilm formation of S3, S5 and S11 in which these strains required longer time to adapt on the substrata before forming biofilms.

\section{Development of biofilm on biotic surfaces (Jelutong paya hardwood)}

From Figure 3, strain G14 formed the strongest $(2.283 \pm 0.180)$ biofilm on the wood surfaces based on the crystal violet staining. For saprophytic strains, S12 had the highest quantity of biofilm whereas S3 had the lowest amount of biofilm by observing on the mean optical density values of each isolates. The adhesion of bacterial cells on the wood surface started at day $1^{\text {st }}$ till day $6^{\text {th }}$ with the mean optical density values at approximately 2.0. S4 and $\mathrm{S} 12$ had the highest starting optical density values (day $1^{\text {st }}$ ) with 2.071 and 2.081 respectively. At the highest biofilm cells saturation (day $6^{\text {th }}$ ), the mean optical density values of the isolates were relatively at 2.3. From Figure 4, saprophytic Leptospira, S12 reported had the highest OD readings $(2.310 \pm 0.024)$ while $S 12$ recorded as the lowest optical density value which is $1.980 \pm 0.024$ on day $11^{\text {th }}$.

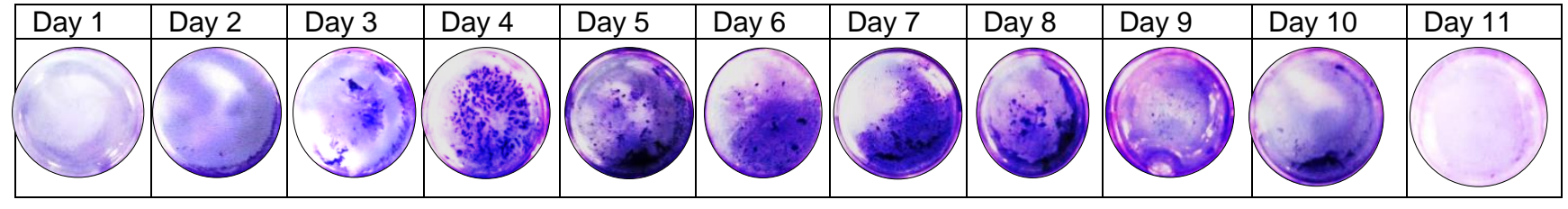

Figure 1: Visualization and quantification of biofilm on microtiter plates of G14 (Leptospira wolffii serovar Khorat strain Khorat-H2). Strongest stained biofilm cells were formed on plates and stained with $0.1 \%$ of crystal violet solution observed for 11 days.

\begin{tabular}{|l|l|l|l|l|l|l|l|l|l|l|}
\hline Day 1 & Day 2 & Day 3 & Day 4 & Day 5 & Day 6 & Day 7 & Day 8 & Day 9 & Day 10 & Day 11 \\
\hline & & & & & & & & & &
\end{tabular}

Figure 2: Visualization and quantification of biofilm on microtiter plates of $S 12$ (L. meyeri strain Semaranga_DB49) as the strongest biofilm in saprophytic. Stained biofilm cells were formed on plates and stained with $0.1 \%$ of crystal violet solution observed for 11 days.

\begin{tabular}{|c|c|c|c|c|c|c|c|c|c|c|}
\hline Day 1 & Day 2 & Day 3 & Day 4 & Day 5 & Day 6 & Day 7 & Day 8 & Day 9 & Day 10 & Day 11 \\
\hline$\frac{19}{2-3}$ & 4 & 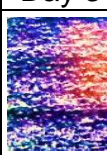 & & 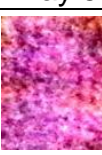 & & 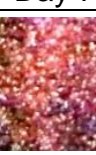 & $5 \%$ & & tor & For \\
\hline
\end{tabular}

Figure 3: Visualization and quantification of biofilm on Jelutong paya hardwood of G14 (L. wolffii serovar Khorat strain Khorat-H2) with $2.333 \pm 0.037$ on day $6^{\text {th }}$ which produced the highest amount of biofilm.

\begin{tabular}{|c|c|c|c|c|c|c|c|c|c|c|}
\hline Day 1 & Day 2 & Day 3 & Day 4 & Day 5 & Day 6 & Day 7 & Day 8 & Day 9 & Day 10 & Day 11 \\
\hline & & & & & & & & & & \\
\hline
\end{tabular}

Figure 4: Visualization and quantification of biofilm on Jelutong paya hardwood of S12 (L. meyeri strain Semaranga_DB49) with $2.283 \pm 0.180$ on day $8^{\text {th }}$. 


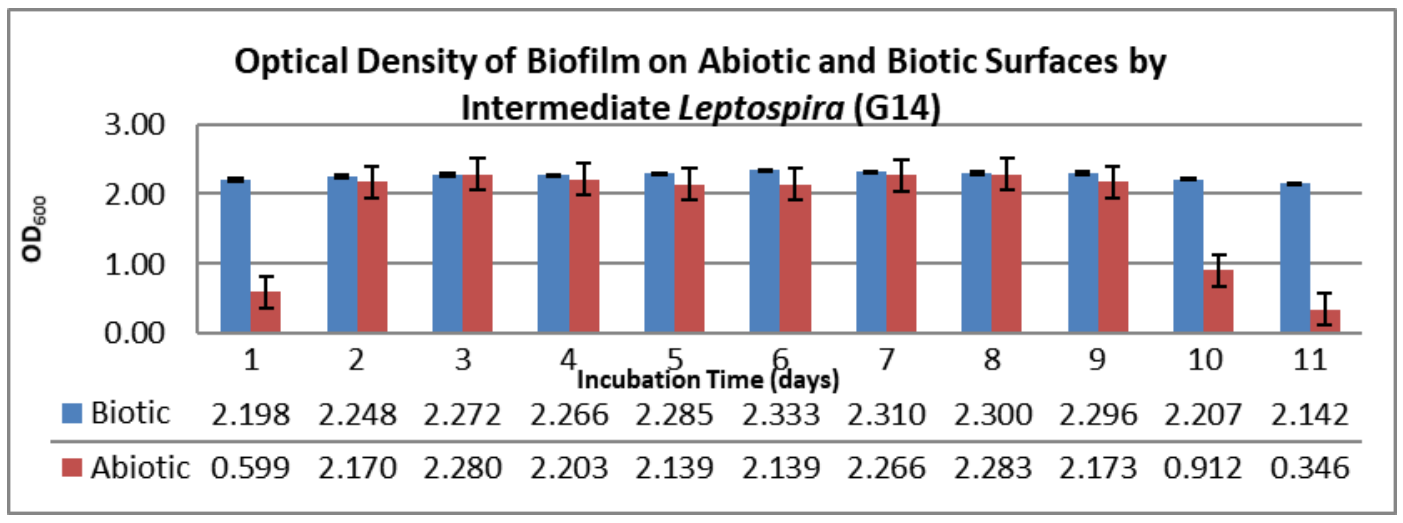

Figure 5: Biofilm formation by strongest intermediate strain, G14 (L. wolffii serovar Khorat strain Khorat-H2) environmental isolates incubated at $30^{\circ} \mathrm{C}$ for 11 days in $\mathrm{EMJH}$ media and measured by $0.1 \%$ crystal violet staining with error bars representing \pm one standard error.

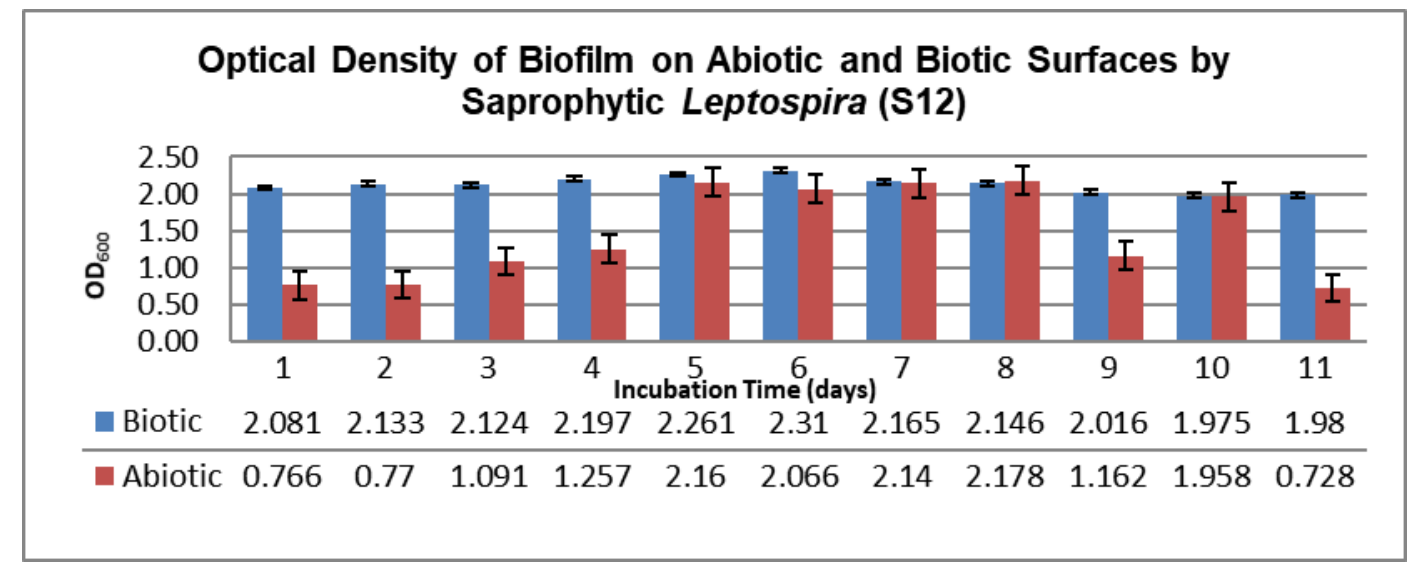

Figure 6: The highest biofilm forming ability by saprophytic strain, S12 (L. meyeri strain Semaranga_DB49) environmental isolates incubated at $30^{\circ} \mathrm{C}$ for 11 days in $\mathrm{EMJH}$ media and measured by $0.1 \%$ crystal violet staining with error bars representing \pm one standard error.

\section{Optical density of Leptospira}

The growth pattern from Figures 5 and 6 show the optical density at $600 \mathrm{~nm}$ of intermediate and saprophytic Leptospira against incubation time for biofilm formation on the abiotic and biotic surfaces, respectively. Both graphs summarized the biotic surface clearly show higher biofilm forming ability in both strains. The biofilms formation trend in intermediate strains was relatively stronger $(O D>2.0)$ from day $2^{\text {nd }}$ while saprophytic attained $O D>2.0$ at day $5^{\text {th }}$.

\section{DISCUSSION}

In this study, the biofilm formation of intermediate and saprophytic Leptospira strains were tested on microtitre plates (abiotic surface) and wood chips (biotic surface). Qualitative analysis by phase contrast microscopy showed that intermediate Leptospira produced more adherent bacterial cells than saprophytic Leptospira. This finding revealed that biofilm formation by Leptospira spp. were able to attach stronger on biotic surfaces and substratum specific than abiotic surface (Figures 3 and 4). Previous studies have reported similar observation where biotic surface produce greater biofilms than abiotic surface (Mueller et al., 2007; Adetunji et al., 2011). For biotic surface, the strains formed biofilms at the beginning of the experiment and gradually increase in the following days (day $2^{\text {th }}$ to day $7^{\text {th }}$ ). Incubation is necessary for the Leptospira cells to transform into a complete whole biofilm. Previous study by Chakraborty et al. (2011) stated that Leptospira strains that were isolated from the environmental samples are considered as a slow growth microorganism. The similar growth pattern was also observed in our study. Statistically, there is significant difference $(p<0.05)$ between the mean of optical density cut-off values and the incubation time in Leptospira strains. Therefore, a longer incubation time (11 days) was needed for Leptospires cell to multiply, adapt and completely turns into biofilms. As demonstrated in Figures 5 and 6, the intensity (OD) of the biofilm shown by crystal violet staining increased significantly with the increased of incubation time. It was shown that the attachment of 
Malays. J. Microbiol. Vol 14(4) Special Issue 2018, pp. 313-319 DOI: http://dx.doi.org/10.21161/mjm.144183

intermediate, G14 at the bottom of the wells was strong adhered throughout the duration of biofilm incubation (day $11^{\text {th }}$ ). These results agree with Briheuga et al. (2012) who reported the biofilms formed by the isolates were resistant to the washes performed in the surfaces at both short and long incubation times.

Biofilm bacteria can form and withstand biofilms at different conditions. The present study found that Leptospira spp. developed biofilm on different surfaces, biotic and abiotic with incubation time. Thus, the survival of Leptospira in environment for a longer period is due to its ability to colonize into a host and cause disease. The surface characteristics and the attachment efficiency of specific strains may also be the factors that affect the bacterial adhesion on surfaces (Elhariry, 2011). This study showed that the biofilm produced by intermediate Leptospira is strong enough to withstand rinsing process, thus indicated the biofilm attachment is irreversible. The strains formed biofilms at the beginning of the experiment and gradually increase in the following days. In this stage, the bacterial cells began to multiply, preconditioning the adhesion surface and adsorb into the surfaces. The surface hydrophobicity increases with the surface roughness where it enhances the bacterial adhesion (Pui et al., 2011). Plant surfaces especially wood surface has a rough texture, appearance and irregular surface that favoured bacterial cell attachment which eventually will develop a robust biofilm. Previously, a study reported that the mean values of pathogenic Leptospira spp. were six times higher than saprophytes (Pui et al., 2017). This finding agrees with Kumar et al. (2015) and implied that saprophytic Leptospira is less pathogen in the environment as it lacks the virulence and host invasion genes. This indicated the level of pathogenicity in saprophytes was lesser than pathogenic Leptospira.

Interestingly, this study found that intermediate and saprophytic Leptospira required 11 days for a complete maturation to detachment of biofilm formation. Previous study showed that pathogenic strains can forms biofilm at approximately OD>21.760 at day $7^{\text {th }}$ (Pui et al., 2017). Based on the optical density cut-off value, the biofilm forming ability of pathogenic strains on abiotic surfaces was 10 times higher that intermediate and saprophytic Leptospira. In agreement of previous study, biofilm formation of bacteria after an extended period of incubation was correlated with the persistent of host infection and survival strategy (Culler et al., 2014).

\section{CONCLUSION}

Leptospira spp., isolated from different sources are capable to form biofilm on abiotic and biotic surfaces. Intermediate strain formed biofilm faster compared to the saprophytic strains. Biofilm formation is an essential factor contributing to bacterial pathogenesis and it can lead to serious implications in medical field, public health, industry and environment. Hence, these results provided better understanding on the potential of biofilm formation by Leptospira on abiotic and biotic surfaces.

\section{ACKNOWLEDGEMENTS}

This study was funded by Ministry of Higher Education Malaysia under Fundamental Research Grant Scheme FRGS/ST03 (02)/1209/2014(10).

Fellowship Award (MyBrain15) to Jennifer Ak Jalan by Minister of Higher Education Malaysia is duly acknowledged.

\section{REFERENCES}

Adetunji, V. O. and Isola, T. O. (2011). Crystal violet assay for assessment of biofilm formation by Listeria monocytogenes and Listeria spp. on wood, steel and glass surfaces. Global Veterinaria 6(1), 6-10.

Benacer, D., Woh, P. Y., Zain, S. N., Amran, F. and Thong, K. L. (2013). Pathogenic and saprophytic Leptospira species in water and soils from selected urban sites in peninsular Malaysia. Microbes and Environments 28(1), 135-140.

Briheuga, B., Samartino, L., Auteri, C., Venzano, A. and Caimi, K. (2012). In vivo cell aggregations of a recent swine biofilm-forming isolate of Leptospira interrogans strain from Argentina. Revista Argentina de Microbiologia 44(2), 138-143.

Chakraborty, A., Miyahara, S., Villanueva, S. Y., Saito, M., Gloriani, N. G. and Yoshida, S. (2011). A novel combination of selective agents for isolation of Leptospira species. Microbiology and Immunology 55(11), 494-501.

Culler, H. E., Mota, C. M., Abe, C. M., Sircili, M. P. and Franzolin, M. R. (2014). Atypical Enteropathogenic Escherichia coli strains form biofilm on abiotic surfaces regardless of their adherence pattern on cultured epithelial cells. Bio Med Research International 2014(2014), 845147.

Elhariry, H. M. (2011). Attachment strength and biofilm forming ability of Bacillus cereus on green-leafy vegetables: Cabbage and lettuce. Food Microbiology 28(2011), 1266-1274.

Guerra M. A. (2009). Leptospirosis. Journal American Veterinary Medical Association 234, 472-478.

Iraola, C., Spangenberg, L., Bastos, B. L., Grana, M., Vasconcelos, L., Almeida, A., Grief, G., Robello, C., Ristow, P. and Naya, H. (2016). Transcriptome sequencing reveals wide expression reprogramming of basal and unknown genes in Leptospira biflexa biofilms. American Society of Microbiology 1(2), 1642.

Kumar, K. V., Lall, C., Raj, R. V., Vedhagiri, K., Kartick, V., Surya, P., Natarajaseenivasan, K. and Vijayachari, P. (2015). Overexpression of heat shock GroEL stress protein in leptospiral biofilm. Microbial Pathogenesis 2, 8-11.

Ministry of Health Malaysia (2015). Epidemiology and Current Situation of Leptospirosis in Malaysia. Available from http://jkt.kpkt.gov.my/resources/index /pdf/Persidangan 2015/persidangan\%20kesihatan/Le ptospirosis in Malaysia.pdf [Retrieved 10 October 2015]. 
Mueller, R. S., McDougald, D., Cusumano, D., Sodhi, N., Kjelleberg, S., Azam, F. and Bartlett, D. H. (2007). Vibrio cholerae strains possess multiple strategies for abiotic and biotic surface colonization. Journal of Bacteriology 189(14), 5348-5360.

Pui, C. F., Wong, W. C., Chai, L. C., Lee, H. Y., Nillian, E., Ghazali F. M., Cheah, Y. K., Nakaguchi, Y., Nishibuchi, M. and Radu, S. (2011). Simultaneous detection of Salmonella spp., Salmonella typhi and Salmonella typhimurium in sliced fruits using multiplex PCR. Food Control 22, 337-342.

Pui, C. F., Bilung, L, M., Su'ut, L. and Apun, K. (2015). Prevalence of Leptospira species in environmental soil and water from national parks in Sarawak, Malaysia. Borneo Journal of Resource Science and Technology 5(1), 49-57.

Pui, C. F., Apun, K., Jalan, J., Bilung, L. M., Su'ut, L. and Fatma, H. H. (2017). Microtiter plate assay for the quantification of biofilm formation by pathogenic Leptospira. Research Journal of Microbiology 12(2), 146-153.

Ristow, P., Bourhy, P., Kerneis, S., Schmitt, C., Prevost, M., Lilenbaum, W. and Picardeau, M. (2008). Biofilm formation by saprophytic and pathogenic leptospires. Microbiology 154(5), 13091317.

Russ, A., R., Alek, T. A. and Ghazally, I. (2003). Seroepidemiological study of leptospirosis among the indigenous communities living in the periphery of Crocker Range Park Sabah, Malaysia. ASEAN Review of Biodiversity and Environmental Conservation, (ARBEC). January-March 2003.

Stepanovic, S., Vukovic, D., Dakic, I., Savic and Svabic-Vlahovic, M. (2000). A modified microtiterplate test for quantification of Staphylococcal biofilm formation. Journal of Microbiological Methods 40, 175179.

Sutton, S. (2006). Measurement of microbial cells by optical density. Journal of Validation Technology, 17(1), 46-48.

WHO (1999). Leptospirosis worldwide, 1999. Weekly Epidemiol Record 74, 237-242. 